\title{
Transient Elastography Discloses IDEntical Distribution of Liver Fibrosis in Chronic Hepatitis C Between HIV-Negative AND HIV-Positive Patients on HAART
}

\author{
F. Grünhage ${ }^{1,2 *}$, J.-C. Wasmuth ${ }^{1 *}$, S. Herkenrath ${ }^{1}$, N. Vidovic ${ }^{3}$, G. Goldmann ${ }^{3}$, J. Rockstroh ${ }^{1}$, \\ F. Lammert ${ }^{2}$, J. Oldenburg ${ }^{3}$, T. Sauerbruch ${ }^{1}$, U. Spengler ${ }^{1}$ \\ ${ }^{1}$ Department of Internal Medicine I, University Hospital Bonn, Bonn, Germany, \\ ${ }^{2}$ Department of Internal Medicine II, Saarland University Hospital, Homburg, Germany, \\ ${ }^{3}$ Institute for Experimental Hemostasiology and Transfusion Medicine, University Hospital Bonn, Bonn, Germany
}

\begin{abstract}
Objective: Progressive immunodeficiency associated with HIV-infection leads to a progressive course of liver disease in $\mathrm{HIV} / \mathrm{HCV}$-co-infected patients. Highly active antiretroviral therapy (HAART) efficiently restores and preserves immune functions and has recently been demonstrated to also result in reduced liver-related mortality in $\mathrm{HIV} / \mathrm{HCV}$-co-infected patients. Methods: To analyse differences in current liver fibrosis as a possible effect of HAART on fibrosis progression we assessed hepatic fibrosis by transient elastography in a cross-sectional comparison between HCV-monoinfected and HIV/HCV-co-infected patients presenting at our outpatient department in 2007.

Results: Overall, we did not find any difference in the distribution of liver stiffness between mono- $(\mathrm{n}=84)$ and double-infected $(\mathrm{n}=57)$ patients $(14.4 \mathrm{kPa}(10.8-$ $18.2)$ versus $12.4 \mathrm{kPa}(9.1$ - 16.1), mean (95\%-CI)). However, in the $8 \mathrm{HIV}+$ patients with CD4 counts $<200 / \mu$ liver stiffness was markedly greater $(18.4 \mathrm{kPa}$ $(0.8-36.0))$ than in HIV+ patients with preserved immunity $(11.5 \mathrm{kPa}(8.4-15.0))$.

Conclusions: These findings are in line with other data that show an improved prognosis of chronic hepatitis $\mathrm{C}$ in HIV+ patients under effective HAART, and may be a hint that fibrosis progression in well-treated $\mathrm{HIV}+$ patients will no longer be different from that in HCV-mono-infected patients.
\end{abstract}

Key words: Liver fibrosis, HIV, HCV, transelastography

\section{INTRODUCTION}

Chronic hepatitis $\mathrm{C}$ is a major cause of hepatocellular injury, activation of hepatic stellate cells, increased deposition of extracellular matrix proteins, and ultimately a profoundly disturbed hepatic micro-architecture. This process is modified by several co-factors such as increased alcohol intake $(>50 \mathrm{~g} / \mathrm{d})$, obesity, insulin resistance, and others [1-10]. Importantly, human im-

\footnotetext{
* Both authors contributed equally to this paper.
}

munodeficiency virus (HIV) co-infection has been identified to dramatically accelerate liver fibrosis in $\mathrm{HIV} / \mathrm{HCV}$-infected patients with advanced immunodeficiency [11-15].

Consequently death from end stage liver cirrhosis or liver cancer had been major factors contributing to death in $\mathrm{HIV} / \mathrm{HCV}$ co-infected patients during the pre-HAART era. Effective HAART has reduced the burden of opportunistic diseases and overall mortality. Thus, deaths related to liver disease have now become one of the most important causes of death in $\mathrm{HIV} / \mathrm{HCV}$ co-infected patients, although the absolute number of deaths due to liver disease has decreased possibly reflecting the beneficial impact of HAART on the speed of liver fibrosis progression [6, 16-18]. For this reason, it has meanwhile been recommended to initiate anti-HCV treatment in patients with HIVco-infection as early as possible to avoid the increased risk of progressive liver disease. On the other hand, effective antiretroviral therapy can improve immune functions, and it has been proposed that preserved immunity may reduce fibrosis progression in $\mathrm{HIV} / \mathrm{HCV}$ co-infected patients and result in reduced liver related mortality $[6,18]$.

The decision to initiate anti-HCV treatment pivotally depends on the assessment of hepatic fibrosis. However, liver histology is obtained by biopsy, i.e. an invasive procedure, which has poor acceptance among patients - in particular in those who require repeated assessment. In addition, liver biopsies are subjected to considerable sampling error, and a high degree of inter-observer variability [19]. Thus, various non-invasive tests have been developed to assess liver fibrosis without the need for a biopsy. Transient elastography measures liver stiffness as an index of liver fibrosis. This procedure is easy to perform and entirely harmless. It enables to assess a greater fraction of the liver as a biopsy, and has been demonstrated to correctly reflect the degree of liver fibrosis in a great variety of different chronic liver diseases [20]. Therefore, we applied this non-invasive technique in a cross-sectional analysis to compare liver fibrosis between HCV and $\mathrm{HIV} / \mathrm{HCV}$ co-infected patients under HAART. 


\section{PATIENTS AND METHODS}

Patients were prospectively recruited between January and December 2007 at the University Hospital of Bonn, Germany. Patients were eligible for the study if they had active HCV or HIV/HCV co-infection with detectable serum HCV-RNA. Patients with body mass index $(\mathrm{BMI})>28$ or perihepatic ascites on abdominal ultrasound were excluded from the study. Informed consent was obtained prior to the study, and the protocol had been approved by our local ethics committee in accordance with the Declaration of Helsinki.

Clinical and demographic data such as age, gender, BMI and medication were recorded in all patients. Detection of anti-HCV, anti-HIV, HCV-RNA, and HIVRNA, as well as determination of HCV genotypes, $\mathrm{HCV}$ and HIV viral loads, CD4 counts, liver function tests and platelet counts were done with standard routine tests as described previously [21]. The AST to platelet ratio index (APRI) was calculated from platelet counts and AST values as a serum surrogate marker of fibrosis [22].

\section{Transient Elastography (TE)}

All patients were examined by TE following previously published guidelines [23-25]. In brief, the tip of the probe transducer was placed on the skin between the rib bones over the right lobe of the liver. Measurement depth was between 25 and $65 \mathrm{~mm}$ below the skin surface. Ten measurements were performed with a minimum success rate of at least $60 \%$. IQR for TE were lower than $20 \%$ of the median for all measurements included in this analysis. The results are expressed as median stiffness of all measurements in kilopascals.

\section{STATISTICS}

Categorical and quantitative variables were compared by Fischer's exact test and the nonparametric MannWhitney-U test, respectively. Mean values in each group were compared by one-way analysis of variance (ANOVA) and Bonferroni correction. Correlations of liver stiffness to biochemical markers or surrogate fibrosis scores and to age were analyzed by non-parametric Spearman rank correlation, and associations of infection status to severe fibrosis or cirrhosis were checked by Fisher's exact test.

\section{RESULTS}

A total number of 147 patients had been screened for the study, but 3 patients in each group had to be excluded because obesity made transient elastography impossible (BMI $>28 \mathrm{~kg} / \mathrm{m} 2)$. Thus, 141 patients - 84 patients with $\mathrm{HCV}$ mono-infection and 57 patients with $\mathrm{HIV} / \mathrm{HCV}$ co-infection - were included into the study.

Clinical characteristics are summarized in Table 1. HCV genotypes were available in 72/84 and 55/57 patients, with genotype 1 being most frequent in either group (69\% vs. $76 \%$ ). In either group $64 \%$ and $85 \%$ of patients were male, and median ages were 48 and
42 years, respectively. Forty-seven $(82.5 \%)$ of the HIVpositive patients received HAART which was mainly based on ritonavir-boosted protease inhibitors in 42 patients $(84 \%)$ and non-nucleoside reverse transcriptase inhibitors in 5 patients $(16 \%)$, respectively. All patients received two nucleoside analogues as backbone of HAART, although none of the patients had stavudine or didanosine as part of their current regimen. 42 of the 47 treated patients $(89 \%$ ) had viral loads below the limit of detection. Immunity was well preserved in our HIV/HCV co-infected patients with CD4 counts below $200 / \mu$ l being detected in only $8(14 \%)$ patients. 7 of the latter were on treatment with HAAR'T at the time of $\mathrm{TE}$.

52 of the 57 HIV-infected patients had been exposed to a median duration of 3661 days of HAART (range 115 - 6209). 31 patients had received stavudine as part of prior regimens (median exposure time 1185 days, range 121 - 3516), and 24 had received didanosine (406 days, 15 - 2685). There was no difference in liver stiffness with regard to prior exposure to stavudine (exposed 8.8, 3.3 - 66.4 vs. not-exposed 6.1, $3.6-$ $30.7 ; \mathrm{p}=0.369)$ or didanosine (exposed 9.2, $4.6-66.4$ vs. not-exposed $6.1,3.3-60.4 ; \mathrm{p}=0.208$ ).

$\mathrm{HIV} / \mathrm{HCV}$ co-infected patients had significantly higher bilirubin $(1.0 \pm 1.0 \mathrm{mg} / \mathrm{dl}$ vs. $0.7 \pm 0.5 ; \mathrm{p}=$ $0.007)$ and lower platelet counts $(155.9 \pm 68.4 \mathrm{G} / \mathrm{l}$ vs. $198.3 \pm 81.0 ; \mathrm{p}=0.001)$ than HCV mono-infected patients but the difference in APRI score did not reach statistical significance $(1.5 \pm 2.3$ vs. $2.7 \pm 5.3)$. Moreover, we did not detect significant differences in AST, ALT and $\gamma$-GT between the groups. Furthermore, clinical and biochemical markers did also not differ between HIV+ patients on PI versus NNRTI-based antiretroviral regimens (data not shown).

\section{LIVER STIFFNESS}

Overall liver stiffness varied from 3.3 to $75 \mathrm{kPa}$ with a mean of $13.6 \mathrm{kPa}$. Of note, liver stiffness was not different between $\mathrm{HCV}$-mono-infected $[14.4 \mathrm{kPa}(10.8-$ 18.2) mean, 95\% confidence interval $(95 \% \mathrm{CI})]$ and $\mathrm{HIV} / \mathrm{HCV}$-co-infected patients $(12.4 \mathrm{kPa}(9.1-16.1)$ $95 \%$ CI) (Fig. 1). Likewise, liver stiffness did not differ between HIV/HCV co-infected patients with or without HAART, whereas liver stiffness in the 8 patients with low CD 4 counts $(<200 / \mu \mathrm{l})$ was markedly increased $[18.4 \mathrm{kPa}(0.8-36.0)]$ as compared to patients with CD4 counts $>200 / \mu \mathrm{l}[11.5 \mathrm{kPa}(8.4-15.0)]$. However, due to the small number of patients with low CD4 counts this difference failed to reach statistical significance $(\mathrm{p}=0.187)$.

Liver stiffness results correlated significantly with bilirubin $(\mathrm{r}=0.35 ; \mathrm{p}<0.001)$, and $\gamma$-GT levels $(\mathrm{r}=$ $0.55 ; \mathrm{p}<0.001)$. In addition, liver stiffness results were also highly significantly correlated with the APRIscore which has been established as a non-invasive laboratory surrogate marker of liver fibrosis and cirrhosis in patients with HCV-mono-infection and $\mathrm{HIV} / \mathrm{HCV}$-co-infection $(\mathrm{r}=0.66, \mathrm{p}<0.001)$.

As the date of HCV acquisition usually is not known, we took age as a possible surrogate of $\mathrm{HCV}$ duration and correlated this with the liver stiffness. Indeed, we found an identical relationship of age and 
Table 1. Clinical Characteristics of the study groups.

\begin{tabular}{|c|c|c|}
\hline & HCV mono-infected & $\mathrm{HIV} / \mathrm{HCV}$ co-infected \\
\hline & $\mathrm{N}=84$ & $\mathrm{~N}=57$ \\
\hline Age, median (range) & $48(21-79)$ & $42(23-58)$ \\
\hline Male, $\mathrm{n}$ & 54 & 49 \\
\hline \multicolumn{3}{|l|}{ HCV genotypes } \\
\hline $1, \mathrm{n}(\%)$ & $59(70 \%)$ & $47(82 \%)$ \\
\hline non-1, n (\%) & $25(30 \%)$ & $10(18 \%)$ \\
\hline \multicolumn{3}{|c|}{ Risk factor for HCV or HIV/HCV infection } \\
\hline i.v. drug abuse, n (\%) & $45(54 \%)$ & $32(56 \%)$ \\
\hline Blood products, n (\%) & 0 & $25(44 \%)$ \\
\hline Unknown, n $(\%)$ & $39(46 \%)$ & 0 \\
\hline HAART $\quad$ No, n $(\%)$ & n.a. & $10(18 \%)$ \\
\hline 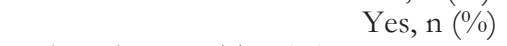 & n.a. & $47(82 \%)$ \\
\hline PI-based HAART, n (\%) & n.a. & $39(84 \%)$ \\
\hline CD4 count, median (range) & n.d. & $430(10-1486)$ \\
\hline $\mathrm{CD} 4<200 / \mu \mathrm{l}, \mathrm{n}(\%)$ & n.d. & $8(14 \%)$ \\
\hline $\operatorname{AST}(\mathrm{U} / \mathrm{l})$, mean $\pm \mathrm{SD}$ & $59.7 \pm 42.4$ & $66.6 \pm 60.1$ \\
\hline $\mathrm{ALT}(\mathrm{U} / \mathrm{l})$, mean $\pm \mathrm{SD}$ & $76.3 \pm 48.8$ & $94.4 \pm 84.3$ \\
\hline$\overline{\mathrm{GGT}}(\mathrm{U} / \mathrm{l})$, mean $\pm \mathrm{SD}$ & $104.0 \pm 128.0$ & $128.0 \pm 129.0$ \\
\hline Bilirubin $(\mathrm{mg} / \mathrm{dl})$, mean $\pm \mathrm{SD}$ & $0.7 \pm 0.5$ & $1.0 \pm 1.0^{*}$ \\
\hline Platelets $(\mathrm{T} / \mathrm{l})$, mean $\pm \mathrm{SD}$ & $198.3 \pm 81.0$ & $155.9 \pm 68.4^{*}$ \\
\hline APRI-score $f$, mean \pm SD & $1.5 \pm 2.3$ & $2.7 \pm 5.3$ \\
\hline \multicolumn{3}{|c|}{ Metavir-Score according to transient elastography ( $\%$ of patients) ${ }^{\circ}$} \\
\hline $\mathrm{F} 0 / 1$ & $42(50 \%)$ & $31(54 \%)$ \\
\hline F2 & $10(12 \%)$ & $5(9 \%)$ \\
\hline F3 & $11(13 \%)$ & $8(14 \%)$ \\
\hline $\mathrm{F} 4$ & $21(25 \%)$ & $13(23 \%)$ \\
\hline
\end{tabular}

$* \mathrm{p}<0.05,+\mathrm{APRI}=\mathrm{AST}$ to platelet ratio. Calculation of APRI-score: AST $/$ Platelet count
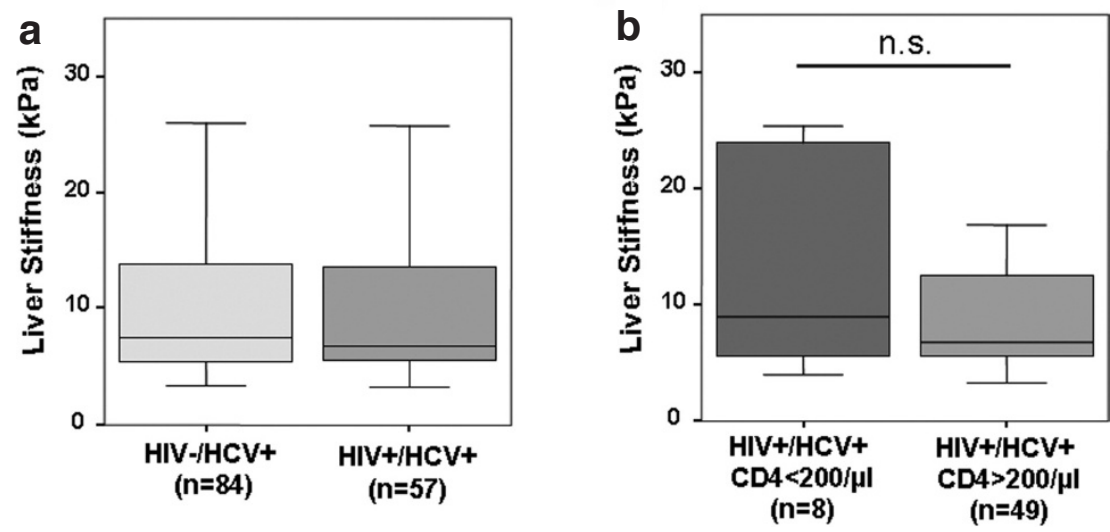

Fig. 1. Cross sectional comparison of liver stiffness in HCV-and HIV/HCV-infected patients. Panel A) illustrates that there is no difference liver in stiffness between HIV/HCV-co-infected versus HCV-mono-infected patients, while panel b) demonstrates a marked difference in liver stiffness between HIV/HCV-co-infected patients with compensated immunity (CD4 counts $>200 / \mu \mathrm{l}$ ) versus patients with advanced immunodeficiency (CD4 counts $<200 / \mu \mathrm{l})$. Data are given as box plots, where the limits of the boxes indicate the 25 th and 75 th percentiles, and the lines inside the boxes the 50 th percentile (median). The whiskers mark the 10th and 90th percentiles, respectively.

liver stiffness in the two patient groups suggesting identical rates of fibrosis progression (annual increase in liver stiffness: HIV pos. $0.31 \pm 0.04 \mathrm{kPa} /$ year; $\mathrm{HIV}$ neg. $0.29 \pm 0.03 \mathrm{kPa} /$ year) (Fig. 2). 
A) HIV neg

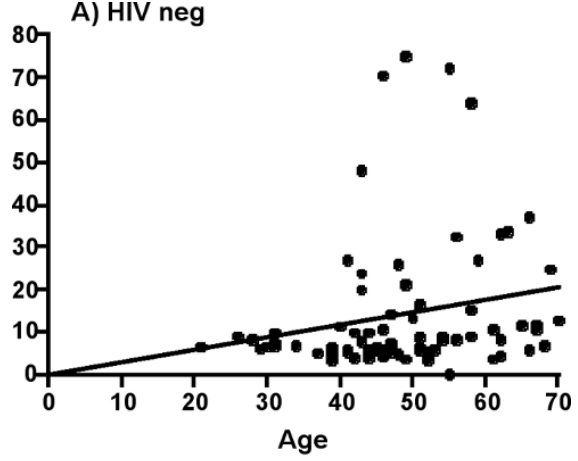

B) HIV pos

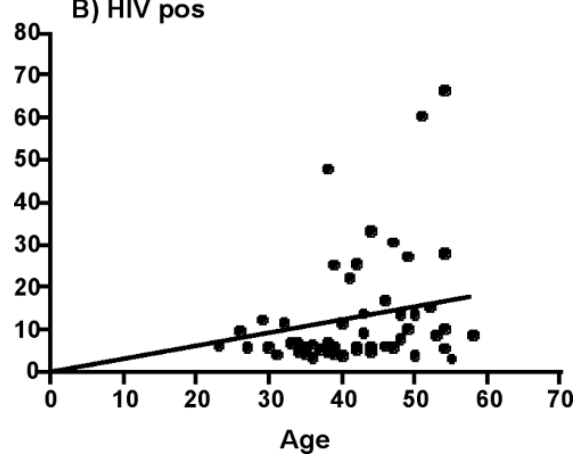

Fig. 2. Correlation of liver stiffness and age as a surrogate marker of disease duration. Panel A shows the correlation in HIV negative patients, Panel B in HIV positive patients. The slope of the regression line is identical in both subsets (HIV pos. $0.31 \pm 0.04 \mathrm{kPa} /$ year; HIV neg. $0.29 \pm 0.03 \mathrm{kPa} /$ year). This indicates that there is no difference with regard to HCV duration between both groups.

\section{DisCUSSION}

Studies from the pre-HAART era suggested that liver fibrosis progressed more rapidly in HIV/HCV co-infected patients than in patients with chronic hepatitis $\mathrm{C}$ alone. When highly active antiretroviral therapy became available it was demonstrated to markedly reduce opportunistic infections but not viral hepatitis. Thus, it was predicted that accelerated progression of fibrosis might become a leading problem in $\mathrm{HIV} / \mathrm{HCV}$ co-infected patients in the HAART era.

Using transient elastography, a highly reliable surrogate test to assess liver fibrosis, our study demonstrated that the distribution of liver fibrosis was identical in HCV mono-infected patients and HIV/HCV-co-infected patients under HAART. Since our study groups reflected all patients $(95.5 \%)$ who had been studied by transient elastography for hepatitis C and HIV/HCV co-infection in 2007, selection bias can largely be excluded and the study groups are representative for $\mathrm{HCV}$ - and HIV/HCV-infected patients in our region. Thus, our results suggest, that increased liver fibrosis is no longer encountered in $\mathrm{HIV} / \mathrm{HCV}$-co-infected patients under HAART as compared to HCV monoinfection. Of note, our results are in line with the previous observation that accelerated liver disease in HIV/HCV co-infection was linked with advanced immunodeficiency [11], and our co-infected patients with
CD4 counts $<200 / \mu \mathrm{l}$ still revealed markedly increased fibrosis. However, this subgroup was rather small and thus did not contribute significantly to the overall distribution of liver fibrosis.

HAART restores CD4 counts and preserves immune functions, which may prevent accelerated progression of fibrosis associated with hepatitis C. For instance, in serial liver biopsies Benhamou and co-workers have directly demonstrated that PI-based antiretroviral therapy can decrease the rate of fibrosis progression in HIV/HCV co-infected patients [6]. Improved fibrosis progression under HAART is further supported by a small number of other studies which reported reduced rates of fibrosis, when HIV co-infection was effectively controlled by HAART [26, 27]. Finally, a decreased rate of fibrosis under HAART may explain, why liver-related mortality is markedly improved under HAART, although antiretroviral drugs do not act directly on HCV replication $[11,18]$.

Liver stiffness was well correlated to platelet counts and the APRI score, surrogate markers, which have also been used to predict fibrosis in HCV and $\mathrm{HIV} / \mathrm{HCV}$ co-infection. Of note, differences in APRI scores were not significant in line with our TE results, while cohort platelet counts were significantly lower in the co-infected group. This difference, however, is more likely to reflect suppressive effects of HIV infection on bone marrow function rather than advanced liver fibrosis [28].

Longer duration of HCV might be associated with advanced stages of fibrosis, as fibrosis is a dynamic process leading to increased fibrosis after long term $\mathrm{HCV}$ infection. In most studies information on exact duration of HCV is not precise. However, we can exclude differences in hepatitis $\mathrm{C}$ duration as a confounding factor for two reasons: First, HIV-positive patients were hemophiliacs to a large extent. This group has been infected in a relatively short time interval during the late 70ies. Second, we found an identical relationship between patient age as a surrogate marker of disease duration and liver stiffness scores in the two patient groups suggesting identical rates of fibrosis progression.

Contrary to our results, several recent studies still continued to report excess morbidity and mortality in HIV/HCV co-infected patients [29-31]. For instance, also using TE de Ledinghen et al. reported increased fibrosis in their co-infected patients despite antiretroviral therapy [29]. However, discrepancies to our study are probably explained by the very low number of patients with advanced immunodeficiency in our cohort. Moreover, an increased prevalence of other co-factors such as drug and alcohol abuse may have contributed to the more unfavourable results in the other studies, whereas our HIV/HCV patients mainly comprised haemophiliac men who have a considerably better prognosis than drug addicts. Although we did not directly assess life-style related parameters as co-factors (especially alcohol use), we are confident from previous studies, that potential bias due to such cofactors is negligible [18]. Finally, the vast majority of our co-infected patients received a PI-based HAART $(83 \%)$, which is known to exert greater antifibrotic activity than other HAART regimens $[6,16,17]$. 
It is noteworthy that the proportion of patients with significant fibrosis and cirrhosis in both groups is large, indicating that many patients have already progressed to fibrosis. Therefore the difference in fibrosis between both groups may be too small as to enable detection of differences in progression rates by a retrospective study.

In summary, our cross-sectional study suggests that the distribution of fibrosis between HCV mono-infected patients and $\mathrm{HIV} / \mathrm{HCV}$ co-infected patients does not differ when immune functions are well preserved under HAART. This observation may be a first hint that in principle effective HAART can reduce fibrosis progression in $\mathrm{HIV} / \mathrm{HCV}$ co-infected patients to the same rate as in HCV mono-infection. Prospective longitudinal studies on large patient cohorts with repeated long-term monitoring of fibrosis progression in HCV-mono-infected as well as $\mathrm{HIV} / \mathrm{HCV}$ co-infected patients are needed to ascertain this attractive hypothesis.

Acknowledgements: Purchase of the Fibroscan system was supported financially by ZLB Behring $\mathrm{GmbH}$, Marburg. There was no influence of design, realisation, analysis of the study or writing of the paper by ZLB Behring.

Conflicts of interest: JO has received reimbursement for attending a symposium/congress, funds for research and fees for consulting from CLS Behring. None of the other authors has personal, financial or any other relations with ZLB Behring.

\section{REFERENCES}

1. Lanternier F, Roulot D, Bentata M, Pol S, Viard JP, Gordien E, Jeantils V, Ziol M, Lortholary O. Risks factors of liver fibrosis in a cohort of intravenous drug users coinfected with HIV and HCV in the HAART era: the role of mixed steatosis. Gastroenterol Clin Biol. 2007 Oct; 31(10): 822-7.

2. Monto A, Kakar S, Dove LM, Bostrom A, Miller EL, Wright TL. Contributions to hepatic fibrosis in HIVHCV coinfected and HCV monoinfected patients. Am J Gastroenterol. 2006 Jul; 101(7): 1509-15.

3. Barreiro P, Martin-Carbonero L, Nunez M, Rivas P, Morente A, Simarro N, Labarga P, Gonzalez-Lahoz J, Soriano V. Predictors of liver fibrosis in HIV-infected patients with chronic hepatitis $\mathrm{C}$ virus (HCV) infection: assessment using transient elastometry and the role of $\mathrm{HCV}$ genotype 3. Clin Infect Dis. 2006 Apr 1; 42(7): 1032-9.

4. Schiavini M, Angeli E, Mainini A, Zerbi P, Duca PG, Gubertini G, Vago L, Fociani P, Giorgi R, Cargnel A. Risk factors for fibrosis progression in $\mathrm{HIV} / \mathrm{HCV}$ coinfected patients from a retrospective analysis of liver biopsies in 1985-2002. HIV Med. 2006 Jul; 7(5): 331-7.

5. Wilson LE, Torbenson M, Astemborski J, Faruki H, Spoler C, Rai R, Mehta S, Kirk GD, Nelson K, Afdhal N, Thomas DL. Progression of liver fibrosis among injection drug users with chronic hepatitis C. Hepatology. 2006 Apr; 43(4): 788-95.

6. Benhamou Y, Di Martino V, Bochet M, Colombet G, Thibault V, Liou A, Katlama C, Poynard T. Factors affecting liver fibrosis in human immunodeficiency virusand hepatitis $C$ virus-coinfected patients: impact of protease inhibitor therapy. Hepatology. 2001 Aug; 34(2): 283-7.

7. Moucari R, Asselah T, Cazals-Hatem D, Voitot H, Boyer N, Ripault MP, Sobesky R, Martinot-Peignoux M, Maylin
S, Nicolas-Chanoine MH, Paradis V, Vidaud M, Valla D, Bedossa P, Marcellin P. Insulin resistance in chronic hepatitis C: association with genotypes 1 and 4, serum HCV RNA level, and liver fibrosis. Gastroenterology. 2008 Feb; 134(2): 416-23.

8. Ryder SD, Irving WL, Jones DA, Neal KR, Underwood JC. Progression of hepatic fibrosis in patients with hepatitis C: a prospective repeat liver biopsy study. Gut. 2004 Mar; 53(3): 451-5.

9. Ortiz V, Berenguer M, Rayon JM, Carrasco D, Berenguer J. Contribution of obesity to hepatitis C-related fibrosis progression. Am J Gastroenterol. 2002 Sep; 97(9): 240814.

10. Franchini M, Rossetti G, Tagliaferri A, Capra F, de Maria E, Pattacini C, Lippi G, Lo Cascio G, de Gironcoli M, Gandini G. The natural history of chronic hepatitis $\mathrm{C}$ in a cohort of HIV-negative Italian patients with hereditary bleeding disorders. Blood. 2001 Sep 15; 98(6): 1836-41.

11. Rockstroh JK, Spengler U, Sudhop T, Ewig S, Theisen A, Hammerstein U, Bierhoff E, Fischer HP, Oldenburg J, Brackmann HH, Sauerbruch T. Immunosuppression may lead to progression of hepatitis $\mathrm{C}$ virus-associated liver disease in hemophiliacs coinfected with HIV. Am J Gastroenterol. 1996 Dec; 91(12): 2563-8.

12. Soto B, Sanchez-Quijano A, Rodrigo L, del Olmo JA, Garcia-Bengoechea M, Hernandez-Quero J, Rey C, Abad MA, Rodriguez M, Sales Gilabert M, Gonzalez F, Miron P, Caruz A, Relimpio F, Torronteras R, Leal M, Lissen E. Human immunodeficiency virus infection modifies the natural history of chronic parenterally-acquired hepatitis $\mathrm{C}$ with an unusually rapid progression to cirrhosis. J Hepatol. 1997 Jan; 26(1): 1-5.

13. Sanchez-Quijano A, Andreu J, Gavilan F, Luque F, Abad MA, Soto B, Munoz J, Aznar JM, Leal M, Lissen E. Influence of human immunodeficiency virus type 1 infection on the natural course of chronic parenterally acquired hepatitis C. Eur J Clin Microbiol Infect Dis. 1995 Nov; 14(11): 949-53.

14. Darby SC, Ewart DW, Giangrande PL, Spooner RJ, Rizza CR, Dusheiko GM, Lee CA, Ludlam CA, Preston FE. Mortality from liver cancer and liver disease in haemophilic men and boys in UK given blood products contaminated with hepatitis C. UK Haemophilia Centre Directors' Organisation. Lancet. 1997 Nov 15; 350(9089): 1425-31.

15. Poynard T, Mathurin P, Lai CL, Guyader D, Poupon R, Tainturier MH, Myers RP, Muntenau M, Ratziu V, Manns M, Vogel A, Capron F, Chedid A, Bedossa P. A comparison of fibrosis progression in chronic liver diseases. J Hepatol. 2003 Mar; 38(3): 257-65.

16. Macias J, Mira JA, Lopez-Cortes LF, Santos I, GironGonzalez JA, Gonzalez-Serrano M, Merino D, Hernandez-Quero J, Rivero A, Merchante N, Trastoy M, Carrillo-Gomez R, Arizcorreta-Yarza A, Gomez-Mateos J, Pineda JA. Antiretroviral therapy based on protease inhibitors as a protective factor against liver fibrosis progression in patients with chronic hepatitis C. Antivir Ther. 2006; 11(7): 839-46.

17. Tural C, Fuster D, Tor J, Ojanguren I, Sirera G, Ballesteros A, Lasanta JA, Planas R, Rey-Joly C, Clotet B. Time on antiretroviral therapy is a protective factor for liver fibrosis in HIV and hepatitis $\mathrm{C}$ virus (HCV) co-infected patients. J Viral Hepat. 2003 Mar; 10(2): 118-25.

18. Qurishi N, Kreuzberg C, Luchters G, Effenberger W, Kupfer B, Sauerbruch T, Rockstroh JK, Spengler U. Effect of antiretroviral therapy on liver-related mortality in patients with HIV and hepatitis C virus coinfection. Lancet. 2003 Nov 22; 362(9397): 1708-13.

19. Bedossa P, Dargere D, Paradis V. Sampling variability of liver fibrosis in chronic hepatitis C. Hepatology. 2003 Dec; 38(6): 1449-57. 
20. Pinzani M, Vizzutti F, Arena U, Marra F. Technology Insight: noninvasive assessment of liver fibrosis by biochemical scores and elastography. Nat Clin Pract Gastroenterol Hepatol. 2008 Feb; 5(2): 95-106.

21. Nattermann J, Vogel M, Berg T, Danta M, Baumgarten A, Mayr C, Bruno R, Tural C, Klausen G, Clotet B, Lutz T, Grunhage F, Rausch M, Nischalke HD, Schewe K, Bienek B, Haerter G, Sauerbruch T, Rockstroh JK, Spengler $\mathrm{U}$. Effect of the interleukin-6 C174G gene polymorphism on treatment of acute and chronic hepatitis $\mathrm{C}$ in human immunodeficiency virus coinfected patients. Hepatology. 2007 Oct; 46(4): 1016-25.

22. Wai CT, Greenson JK, Fontana RJ, Kalbfleisch JD, Marrero JA, Conjeevaram HS, Lok AS. A simple noninvasive index can predict both significant fibrosis and cirrhosis in patients with chronic hepatitis C. Hepatology. 2003 Aug; 38(2): 518-26.

23. Sagir A, Erhardt A, Schmitt M, Haussinger D. Transient elastography is unreliable for detection of cirrhosis in patients with acute liver damage. Hepatology. 2008 Feb; 47(2): 592-5.

24. Fraquelli M, Rigamonti C, Casazza G, Conte D, Donato MF, Ronchi G, Colombo M. Reproducibility of transient elastography in the evaluation of liver fibrosis in patients with chronic liver disease. Gut. 2007 Jul; 56(7): 968-73.

25. Sandrin L, Fourquet B, Hasquenoph JM, Yon S, Fournier C, Mal F, Christidis C, Ziol M, Poulet B, Kazemi F, Beaugrand M, Palau R. Transient elastography: a new noninvasive method for assessment of hepatic fibrosis. Ultrasound Med Biol. 2003 Dec; 29(12): 1705-13.

26. Brau N, Salvatore M, Rios-Bedoya CF, Fernandez-Carbia A, Paronetto F, Rodriguez-Orengo JF, Rodriguez-Torres M. Slower fibrosis progression in HIV/HCV-coinfected patients with successful HIV suppression using antiretroviral therapy. J Hepatol. 2006 Jan; 44(1): 47-55.

27. Souza AR, Tovo CV, Mattos AA, Chaves S. There is no difference in hepatic fibrosis rates of patients infected with hepatitis $C$ virus and those co-infected with HIV. Braz J Med Biol Res. 2008 Mar; 41(3): 223-8.
28. Spivak JL, Bender BS, Quinn TC. Hematologic abnormalities in the acquired immune deficiency syndrome. Am J Med. 1984 Aug; 77(2): 224-8.

29. de Ledinghen V, Barreiro P, Foucher J, Labarga P, Castera L, Vispo ME, Bernard PH, Martin-Carbonero L, Neau D, Garcia-Gasco P, Merrouche W, Soriano V. Liver fibrosis on account of chronic hepatitis $\mathrm{C}$ is more severe in HIV-positive than HIV-negative patients despite antiretroviral therapy. J Viral Hepat. 2008 Jun; 15(6): 427-33.

30. Valle Tovo C, Alves de Mattos A, Ribeiro de Souza A, Ferrari de Oliveira Rigo J, Lerias de Almeida PR, Galperim B, Riegel Santos B. Impact of human immunodeficiency virus infection in patients infected with the hepatitis C virus. Liver Int. 2007 Feb; 27(1): 40-6.

31. Pineda JA, Garcia-Garcia JA, Aguilar-Guisado M, RiosVillegas MJ, Ruiz-Morales J, Rivero A, del Valle J, Luque R, Rodriguez-Bano J, Gonzalez-Serrano M, Camacho A, Macias J, Grilo I, Gomez-Mateos JM. Clinical progression of hepatitis $\mathrm{C}$ virus-related chronic liver disease in human immunodeficiency virus-infected patients undergoing highly active antiretroviral therapy. Hepatology. 2007 Sep; 46(3): 622-30.

Received: November 3,2009 / Accepted: December 7, 2009

Address for correspondence:

Ulrich Spengler, MD

Department of Internal Medicine I

University Hospital Bonn

Sigmund Freud Str. 25

53105 Bonn

Germany

Phone: $\quad+4922828716789$

Fax: $\quad+4922828719822$

Email: ulrich.spengler@ukb.uni-bonn.de 